\title{
BINOCULAR VISION OF MINERS WITH NYSTAGMUS*
}

\author{
BY
}

\section{ARTHUR SMITH AND R. C. BROWNE}

\author{
From the Sunderland Eye Infirmary and the Nuffield Department of Industrial Health, \\ University of Durham
}

The classical studies of coal miners' nystagmus were monocular in outlook, but the rise of orthoptics, the work of Campbell and others $(1948,1951)$, and the suggestion by Browne (1951) that miners' nystagmus may be a type of disuse atrophy of the visual apparatus, have all focused attention upon the binocular vision of the miner with this disease. The objects of the present investigation are to consider the following:

(1) Effect of age and nystagmus on visual acuity.

(2) Relation of eye oscillation, head tremor, and visual acuity.

(3) Action of nystagmus upon the binocular functions of fusion, stereopsis, adduction, and abduction.

(4) Convergence in the different postures assumed in miners' work.

\section{Methods}

Control of Comparison.-The material comprised 47 consecutive patients with nystagmus from County Durham who had all been granted certificates of disablement for this disease by the same medical practitioner. They were matched with a control series of 50 normal men chosen from the same group of 29 collieries at which the men with nystagmus had been working when certified. These collieries were visited, and the names of the controls were selected at random from the office records to match the men with nystagmus, by age (as far as possible to the nearest decade) and occupation. All but three of the controls attended for examination. $\dagger$ The schedules of two men who attended were not completed.

Some of the patients' eyes were oscillating so badly that they could not be examined completely, and their figures cannot therefore be included in the results presented here. If these patients had been included, the contrast between the men with nystagmus and those without would have been even more marked.

Examination of Eyes.- One afternoon a week was set apart for this work to avoid the bustle of normal out-patient conditions. The visual acuity, ophthalmoscopic data, and symptoms and signs of nystagmus, including oscillation of the eyes and head tremor, were recorded on a special schedule, together with a full orthoptic report of the binocular mechanism. Convergence power, measured by the Livingston binocular gauge, received particular attention, as this function was found to be more suitable for the postural tests. The synoptophore is not sufficiently adaptable for extreme angles of vision, and the effect of changes of posture cannot be accurately measured with it. The convergence power was recorded in three positions, with the patient upright, but altering

* Received for publication March 14, 1953.

+ One developed nystagmus after his name had been selected, one had " never been able to pull himself together" since his son was killed 7 years before, and the mere thought of attending hospital upset him, and the third was a man of a suspicious turn of mind who could not understand the method of selection. 
his line of vision from upwards to level, and then downwards. It was also measured in three other positions, in each of which the patient held his line of vision level but altered his posture. The three postures were: stooping with the head thrown back, standing upright with the head straight, and leaning backwards with the head forward. These postural tests were made in the hope that some light might be thrown on a possible relation between the disorder of the oculo-motor system and the unnatural working attitudes caused by the conditions underground.

Statistical Analysis.-For every group of figures a mean and its standard error were calculated and a Student's " $t$ " test of significance was applied to the differences between means. When the probability against the difference between two means being due to chance was 20 or more to 1 , it was considered " significant". Because of the inevitable exclusion of the worst cases of nystagmus, this gives a stringent level of significance in contrasting the patients with the controls.

\section{Results}

Visual Acuity.-It is well known clinically that nystagmus reduces visual acuity, and in this investigation the extent of this reduction can be measured. Table I shows that the normal miners had a visual acuity of about $6 / 9$, whereas the men with nystagmus had one of only $6 / 16(6 / 18$ to the nearest line on the Snellen chart.)

TABLE I

MEAN VISUAL ACUITY

\begin{tabular}{|c|c|c|c|c|c|}
\hline Eye & Control & Nystagmus & Difference & $\begin{array}{c}\text { Standard } \\
\text { Error } \\
+ \text { or }-\end{array}$ & $\begin{array}{l}\text { Difference } \\
\text { Significant }\end{array}$ \\
\hline $\begin{array}{l}\text { Right } \\
\text { Left }\end{array}$ & 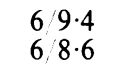 & $\begin{array}{l}6 / 16 \cdot 0 \\
6 / 16 \cdot 1\end{array}$ & $\begin{array}{ll}6 & 6 \cdot 6 \\
6 & 7 \cdot 5\end{array}$ & $\begin{array}{l}1 \cdot 3 \\
1.5\end{array}$ & $\begin{array}{l}\text { Yes } \\
\text { Yes }\end{array}$ \\
\hline
\end{tabular}

The two groups were divided into two sections above and below the 50 birthday to see whether this deterioration took place irrespective of age. Under 50 there was an average acuity of 66 in the controls and $6 / 12$ in the men with nystagmus, and over 50 the averages were $6 / 12$ and $6 / 18$. All these differences appear unlikely to be due to chance (Table II).

TABLE II

MEAN VISUAL ACUITY UNDER AND OVER 50 YEARS OF AGE

\begin{tabular}{|c|c|c|c|c|c|c|}
\hline Eye & $\begin{array}{l}\text { Age } \\
\text { (yrs) }\end{array}$ & Control & Nystagmus & Difference & $\begin{array}{c}\text { Standard } \\
\text { Error } \\
+ \text { or - }\end{array}$ & $\begin{array}{l}\text { Difference } \\
\text { Significant }\end{array}$ \\
\hline Right & $\begin{array}{l}\text { Under } 50 \\
\text { Over } 50\end{array}$ & $\begin{array}{ll}6 & 6 \cdot 4 \\
6 & 12 \cdot 4\end{array}$ & $\begin{array}{l:l}6 & 12 \cdot 3 \\
6 & 18 \cdot 0\end{array}$ & 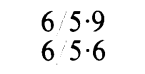 & $\begin{array}{l}1 \cdot 5 \\
2 \cdot 0\end{array}$ & Yes \\
\hline Left & $\begin{array}{l}\text { Under } 50 \\
\text { Over } 50\end{array}$ & $\begin{array}{ll}6 & 5 \cdot 7 \\
6 & 11 \cdot 6\end{array}$ & $\begin{array}{ll}6 & 12 \cdot 7 \\
6 & 18 \cdot 1\end{array}$ & $\begin{array}{ll}6 & 7 \cdot 0 \\
6 & 6 \cdot 5\end{array}$ & $\begin{array}{l}1 \cdot 8 \\
2 \cdot 3\end{array}$ & Yes \\
\hline
\end{tabular}

Since this poor vision is thought to be due to macular suppression from the constant movement of the eyes by both the oscillation and the head 
tremor, it is important to consider what is the acuity of men who suffer from these symptoms compared with that of those who do not. When the effects of oscillation and tremor upon visual acuity are considered, there appears to be little or no association between the two symptoms. Twenty (43 per cent.) men had oscillation of the eyes, and 24 (51 per cent:) had head tremor, whilst only 12 ( 25 per cent.) had both (Table III).

TABLE III

NUMBER OF MEN WITH NYSTAGMUS WHO SHOWED EYE OSCILLATION AND/OR HEAD TREMOR

\begin{tabular}{|c|c|c|c|c|c|c|c|}
\hline \multicolumn{5}{|c|}{ Symptom } & Oscillations & $\begin{array}{c}\text { No } \\
\text { Oscillations }\end{array}$ & Total \\
\hline $\begin{array}{l}\text { Head Tremor } \ldots \\
\text { No Head Tremor }\end{array}$ & $\begin{array}{l}\cdots \\
\cdots\end{array}$ & $\begin{array}{l}\ldots \\
\cdots\end{array}$ & $\begin{array}{l}\ldots \\
\cdots\end{array}$ & $\begin{array}{l}\ldots \\
\cdots\end{array}$ & $\begin{array}{r}12 \\
8\end{array}$ & $\begin{array}{l}12 \\
15\end{array}$ & $\begin{array}{l}24 \\
23\end{array}$ \\
\hline Total & $\ldots$ & $\ldots$ & $\ldots$ & $\ldots$ & 20 & 27 & 47 \\
\hline
\end{tabular}

This suggests that the two symptoms are independent of each other. Moreover, there are almost as many men with tremor amongst those without eye oscillation as amongst those with it. There was very little difference between the visual acuity of those with and without oscillation of the eyes, but the acuity of the men with head tremor was, rather surprisingly, better than that of those without it. Table IV shows that visual acuity was $6 / 18$ in men with oscillations and $6 / 15$ in those without.

TABLE IV

EFFECT OF HEAD TREMOR AND OSCILLATION ON VISUAL ACUITY

\begin{tabular}{|c|c|c|c|c|c|c|}
\hline \multirow{2}{*}{$\begin{array}{lll}\text { Eye } & \ldots & \ldots \\
& & \text { Sign }\end{array}$} & \multirow[t]{2}{*}{$\ldots$} & \multirow[t]{2}{*}{$\ldots$} & \multicolumn{2}{|c|}{ Left } & \multicolumn{2}{|c|}{ Right } \\
\hline & & & $\begin{array}{l}\text { Visual } \\
\text { Acuity }\end{array}$ & $\begin{array}{l}\text { Difference } \\
\text { Significant }\end{array}$ & $\begin{array}{l}\text { Visual } \\
\text { Acuity }\end{array}$ & $\begin{array}{l}\text { Difference } \\
\text { Significant }\end{array}$ \\
\hline $\begin{array}{l}\text { Head tremor ... } \\
\text { No head tremor } \\
\text { Oscillation ... } \\
\text { No oscillation }\end{array}$ & $\begin{array}{l}\cdots \\
\cdots \\
\cdots \\
\cdots\end{array}$ & $\begin{array}{l}\cdots \\
\cdots \\
\cdots \\
\cdots\end{array}$ & $\begin{array}{l}6 / 12 \cdot 3 \\
6 / 20 \cdot 1 \\
6 / 18 \cdot 2 \\
6 / 14 \cdot 8\end{array}$ & Yes & $\begin{array}{l}6 / 12 \cdot 3 \\
6 / 20 \cdot 3 \\
6 / 17 \cdot 3 \\
6 / 15 \cdot 0\end{array}$ & $\begin{array}{l}\text { Yes } \\
\text { No }\end{array}$ \\
\hline
\end{tabular}

This difference is small and is likely to be due to chance. Visual acuity in men with tremor of the head, however, was $6 / 12$, but only $6 / 20$ in those without - a large and significant difference. This finding was subjected to a closer scrutiny and Table V (opposite) shows that when eye oscillation and head tremor come together in the same patient, visual acuity is $6 / 11$, but when they are found apart it is only $6 / 28,6 / 16$, or $6 / 13$, for the left eye. The figures for the right eye show similar differences. The records of one man who was unable to see a Snellen chart at all, because of complete central suppression, have been excluded from these Tables. He was suffering from both head tremor and eye oscillation, but their mutual effect could not be measured because he could not see. 
TABLE $\mathrm{V}$

COMBINED EFFECT OF HEAD TREMOR AND OSCILLATION

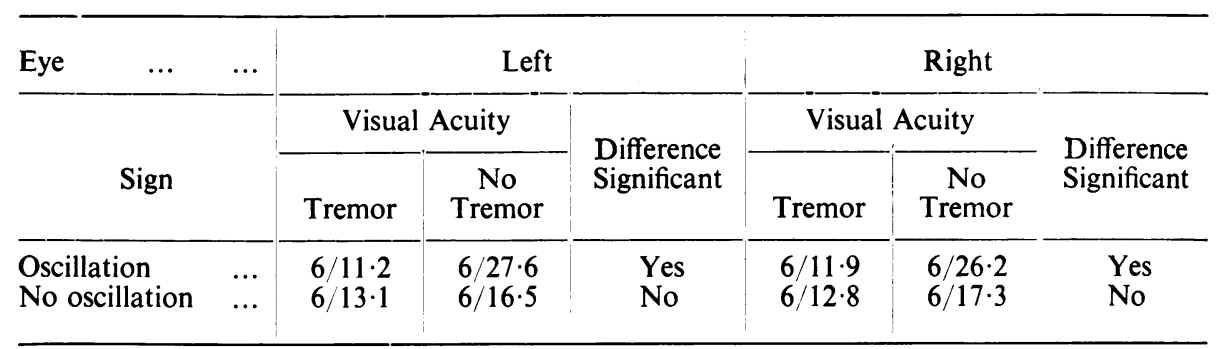

Fusion Angle.-There is a very small difference between the nystagmus patients and the controls in the fusion test, and it may be concluded that here the disease has little or no effect. The mean fusion angles are:

controls $0.6^{\wedge} \pm 0.3^{\circ}$;

nystagmus patients $0.7^{\circ} \pm 0.3^{\circ}$.

In both groups, age had the effect of increasing the fusion angle:

\begin{tabular}{l|c|c} 
Age & under 50 & over 50 \\
\hline Controls _.. $\ldots$ & $0 \cdot 4^{\circ}$ & $0 \cdot 8^{\circ}$ \\
Nystagmus patients... & $0 \cdot 4^{\circ}$ & $0 \cdot 9^{\circ}$
\end{tabular}

Stereopsis.-In this test there was a significant decrease in the number of men with nystagmus who had full stereoscopic vision. Controls had 93 per cent., and the nystagmus patients only 52 per cent. Age, eye oscillation, and head tremor appeared to have little effect on the results.

Abduction and Adduction.-There were no detectable differences in the angles of abduction: controls $3.5^{\circ} \pm 0.1^{\circ}$; nystagmus patients $3.2^{\circ} \pm 0.1^{\circ}$. But in the case of adduction the difference was significant to the disadvantage of the patients: controls $19.8^{\circ} \pm 1.4^{\circ}$; nystagmus patients $15.2^{\circ} \pm 1.4^{\circ}$. Neither tremor, eye oscillations, nor age appeared to have any effect.

Convergence.-Six tests were conducted on the Livingston binocular gauge (Table VI). In every instance the convergence power of the group

TABLE VI

CONVERGENCE POWER AS MEASURED ON LIVINGSTON BINOCULAR GAUGE (cm.)

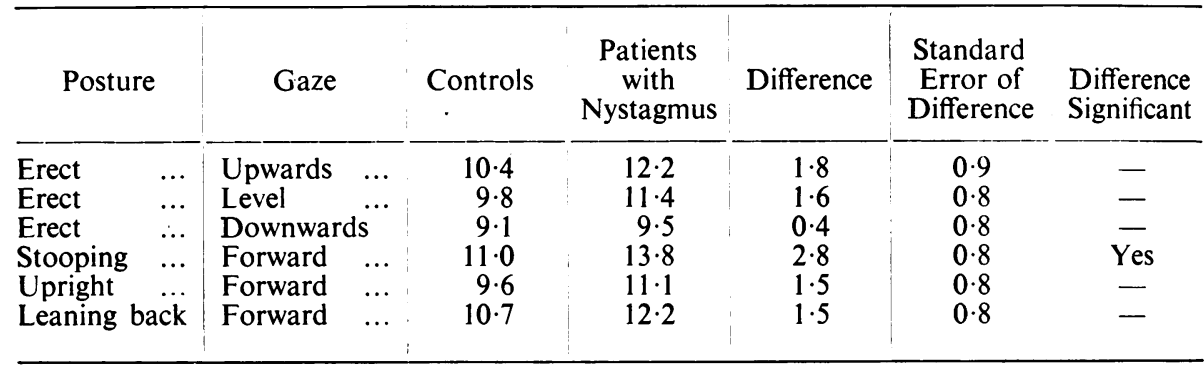


with nystagmus was poorer than that of the control group, but the individual variation within both of these groups was so great that only one of the differences between the means was statistically significant. This occurred in the test in which the patient is stooping with his head thrown back but with his gaze horizontally forward. Here, the convergence power of the normal men was $11.0 \mathrm{~cm}$. and of those with nystagmus $13.8 \mathrm{~cm}$. It may be that, if larger samples had been taken in both groups, all the results would have been significant.

The effect of the disease seems to be more marked on the convergence power of the younger men. Under fifty years of age the binocular gauge reading for the control group was $9.2 \mathrm{~cm}$., but for the nystagmus patients it was $13.5 \mathrm{~cm}$. (difference $4.3 \mathrm{~cm}$.). The corresponding figures for men over 50 were, controls $11.4 \mathrm{~cm}$., nystagmus patients $13.9 \mathrm{~cm}$. (difference $2.5 \mathrm{~cm}$.). The effects of oscillation of the eyes and tremor of the head upon convergence power were both small, and might both have been due to chance.

\section{Discussion}

The fact that head tremor seems to improve the visual acuity of men with eye oscillation appears to be a new finding. This observation requires more numerical support than the present paper has been able to afford it, if only because the figures in Table $V$ suggest that the visual acuity of a man with both oscillation and tremor (6/11.2 for the left eye) is rather, but not signifis cantly, better than that of a man with neither. This is not a function of age since the average age of those with both was 55, and the average age of those with neither oscillation nor tremor was 54 . However, this finding receives some confirmation from a slow-motion film used by one of us (R.C.B.) for teaching, which shows that when the eyes oscillate to the right the coarse tremor of the head in opposite phase turns it to the left, and vice versa. The two motions thus appear to cancel each other out and leave the eye unmoved in respect of any external object at which it is looking.

There are at least two kinds of head tremor in these patients, one with low frequency and high amplitude, which may be compensatory, and another with high frequency and low amplitude, which resembles that produced by prolonged maximum contraction of almost any muscle group. These both appear in clinical notes as "tremor," and it is not surprising that statistical analysis leaves the matter not yet entirely clear.

Campbell and others (1948) found that the average angle of adduction in normal miners at 0.22 foot candles was $19^{\circ}$, which, in so far as a comparison can be made, agrees with the $19 \cdot 8^{\circ}$ of the present paper. For the nystagmus patients their figure was $13.0^{\circ}$ compared with the $15.0^{\circ}$ found here. In a later paper (1951) they further showed that both adduction and stereoscopic vision are normal in miners before they get nystagmus. But the present paper suggests that only 52 per cent. of the men with nystagmus have full stereopsis, as compared with 93 per cent. of normal miners. 
If the complementary pictures of the disease given by these three papers are fused, it can perhaps be said that, in addition to the more obvious physical signs of nystagmus, the disease makes it difficult to adduct the eyes, especially when stooping, even though there is over-convergence in some men. There is macular suppression and the stereoscopic vision deteriorates. Oscillation of the eyes makes the visual acuity less than normal, but this tends to be neutralized if there is a head tremor as well.

\section{Summary}

(1). An ophthalmological examination of 47 coal miners with nystagmus, and 45 men without, has been made. The control group without the disease was chosen at random, but the men in it matched the men with nystagmus in respect of age, occupation, and place of work.

(2). The visual acuity of men with nystagmus was 618 and that of the controls 69 (to the nearest line of the Snellen chart).

(3). The men with nystagmus who had both tremor of the head and oscillation of the eyes had better visual acuity than those with one or other of these symptoms alone.

(4). The angles of fusion and of abduction were no different in the two groups.

(5). Nystagmus reduced the angle of adduction from $20^{\circ}$ in the control group to $15^{\circ}$ in the group with the disease.

(6). Only 52 per cent. of the men with nystagmus, compared with 93 per cent. of the controls, had full stereoscopic vision.

(7). Convergence in the men with nystagmus was worse than in the controls, especially when stooping with the head thrown back and looking horizontally.

Acknowledgments are due to Miss Strother for performing the orthoptic tests, to the National Coal Board for an expenses grant, to the National Union of Mineworkers (Durham Area) for help in the organization of the survey, and to Mr. H. Campbell for statistical advice.

\section{REFERENCES}

Browne, R. C. (1951). Lancet, 1, 721.

Campbell, D. A., Harrison, R., and Vertigen, J. (1948). British Journal of Ophthalmology, 32, 226 . 